\title{
Video Article \\ Target Cell Pre-enrichment and Whole Genome Amplification for Single Cell Downstream Characterization
}

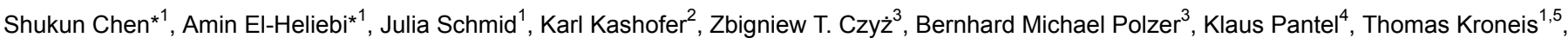 \\ Peter Sedlmayr ${ }^{1}$ \\ ${ }^{1}$ Institute of Cell Biology, Histology and Embryology, Medical University of Graz \\ ${ }^{2}$ Institute of Pathology, Medical University of Graz \\ ${ }^{3}$ Fraunhofer Institute for Toxicology and Experimental Medicine ITEM \\ ${ }^{4}$ Department of Tumor Biology, University Medical Center Hamburg-Eppendorf \\ ${ }^{5}$ Sahlgrenska Cancer Center, University of Gothenburg \\ *These authors contributed equally
}

Correspondence to: Thomas Kroneis at thomas.kroneis@medunigraz.at

URL: https://www.jove.com/video/56394

DOI: doi:10.3791/56394

Keywords: Cancer Research, Issue 135, rare cell analysis, single cell analysis, whole genome amplification, array comparative genome hybridization, in vivo isolation device, targeted next generation sequencing, next generation sequencing immunofluorescence labelling

Date Published: 5/15/2018

Citation: Chen, S., El-Heliebi, A., Schmid, J., Kashofer, K., Czyż, Z.T., Polzer, B.M., Pantel, K., Kroneis, T., Sedlmayr, P. Target Cell Pre-enrichment and Whole Genome Amplification for Single Cell Downstream Characterization. J. Vis. Exp. (135), e56394, doi:10.3791/56394 (2018).

\section{Abstract}

Rare target cells can be isolated from a high background of non-target cells using antibodies specific for surface proteins of target cells. A recently developed method uses a medical wire functionalized with anti-epithelial cell adhesion molecule (EpCAM) antibodies for in vivo isolation of circulating tumor cells (CTCs) ${ }^{1}$. A patient-matched cohort in non-metastatic prostate cancer showed that the in vivo isolation technique resulted in a higher percentage of patients positive for CTCs as well as higher CTC counts as compared to the current gold standard in CTC enumeration. As cells cannot be recovered from current medical devices, a new functionalized wire (referred to as Device) was manufactured allowing capture and subsequent detachment of cells by enzymatic treatment. Cells are allowed to attach to the Device, visualized on a microscope and detached using enzymatic treatment. Recovered cells are cytocentrifuged onto membrane-coated slides and harvested individually by means of laser microdissection or micromanipulation. Single-cell samples are then subjected to single-cell whole genome amplification allowing multiple downstream analysis including screening and target-specific approaches. The procedure of isolation and recovery yields high quality DNA from single cells and does not impair subsequent whole genome amplification (WGA). A single cell's amplified DNA can be forwarded to screening and/or targeted analysis such as array comparative genome hybridization (array-CGH) or sequencing. The device allows ex vivo isolation from artificial rare cell samples (i.e. 500 target cells spiked into $5 \mathrm{~mL}$ of peripheral blood). Whereas detachment rates of cells are acceptable ( $50-90 \%)$, the recovery rate of detached cells onto slides spans a wide range dependent on the cell line used $(<10->50 \%)$ and needs some further attention. This device is not cleared for the use in patients.

\section{Video Link}

The video component of this article can be found at https://www.jove.com/video/56394/

\section{Introduction}

Recently, CellCollector DC01, a medical wire functionalized with anti-EpCAM antibodies for isolating CTCs from peripheral blood of cancer patients, was added to the methodical spectrum of CTC enumeration ${ }^{1,2,3}$. In a currently ongoing study in non-metastatic prostate cancer, this functionalized wire reports almost twice as many patients to be CTC-positive and higher CTC counts in CTC-positive patients as compared to CellSearch, the gold standard in CTC enumeration ${ }^{3}$. Due to this encouraging performance, isolation of cells from a functionalized medical wire for single-cell analysis would be desirable, but neither enzymatic treatment with cell detachment solutions (e.g. trypsin) nor laser microdissection allows the recovery of intact cells (data not shown).

To allow the detachment of captured cells, a new generation of functionalized wires was equipped with a specific polymer. This polymer, which links the capture antibodies to the wire, is susceptible to a release buffer treatment allowing detachment of intact cells (CellCollector DC03 referred to as Device). The new functionalized device, allows isolation of target cells from various concentrations of cancer cell line cells spiked into bovine serum albumin (BSA)/phosphate buffered saline (PBS) and peripheral blood, respectively.

To ease the visual detection of cells on the Device and after recovery, the target cancer cells are labelled with carboxyfluorescein succinimidyl ester (CFSE) and a DNA stain before the recovering treatment (i.e. charging and detaching). The treatment's effects on DNA quality of single cells were previously evaluated after WGA by means of a quality control PCR ${ }^{4,5}$, array-CGH ${ }^{6,7}$ and targeted sequencing ${ }^{7}$ showing no difference compared to non-treated cells micromanipulated from cell suspensions ${ }^{7}$. The advantage of this method lies in the combination of rare targetcell pre-enrichment and the recovery of cells for single-cell downstream analysis (Figure 1). The current CE-labelled in vivo collection device 
is generally used for enumeration of CTCs rather than for single-cell molecular characterization ${ }^{2,8}$. However, more comprehensive analysis to investigate heterogeneity among CTCs long for analysis at the individual cell level (i.e. targeted sequencing at the single-cell level). Other cell-based methods are based on immunomagnetic isolation of EpCAM-positive CTCs and single-cell handling based on dielectrophoresis for subsequent molecular genetic analysis ${ }^{9,10}$. Molecular characterization of CTCs is an important requirement for their useful implementation in a clinical setting and is equally important in basic research of the metastatic cascade. In parallel to CTCs, circulating tumor DNA (ctDNA) has become of great importance as it allows DNA analysis of the tumor burden with minimal technical isolation procedures ${ }^{11,12}$. The cell based approaches might serve as a complementary contribution as it allows for RNA ${ }^{13,14}$ and protein ${ }^{15}$ expression analysis and also for CTC derived cell cultures or xenografts ${ }^{16,17}$. Although obstacles such as low cell recovery and clearance for the use in patients still need to be overcome, the catch and release method takes an important next step towards characterization of rare target cells.

\section{Protocol}

All procedures have been approved by the Ethics Committee of the Medical University of Graz (25-240 ex 12/13). Peripheral blood for spiking experiments was sampled from healthy individuals.

NOTE: This protocol describes the isolation of HT-29 cells (human colon cancer cell line) from PBS or from artificial mixtures of HT-29 cells and peripheral blood. The same experiment was performed with two additional cell lines (LNCaP and VCaP, experimental data in Representative Results) and can theoretically be performed with all cells expressing EpCAM.

\section{Preparation of target cells}

1. Cell culture and labelling of cells

NOTE: In this protocol, cells are cultured in $75 \mathrm{~cm}^{2}$ culture flasks. Please adjust the amounts of reagents accordingly if other cell culture devices are used (e.g. $25 \mathrm{~cm}^{2}$ culture dishes, 6-well plates, etc.). All liquids used are pre-warmed to $37^{\circ} \mathrm{C}$ in a water bath. If not indicated otherwise, all protocol steps are performed at room temperature (RT).

1. Culture HT-29 cells in McCoy's 5a Modified Medium supplemented with $2 \mathrm{mM} \mathrm{L-glutamine,} 20 \mathrm{mM}$ Hepes, $10 \%$ fetal bovine serum (FBS), and $1 \%$ penicillin/streptomycin at $37^{\circ} \mathrm{C}$ in a $5 \% \mathrm{CO}_{2}$ atmosphere.

2. When cells are $90 \%$ confluent, remove the medium and rinse the cells with $10 \mathrm{~mL}$ of $1 \times$ PBS.

3. To harvest cells, add $2 \mathrm{~mL}$ of the cell detachment solution (Table of Materials and Reagents) to the cells and incubate the cells for approximately $5 \mathrm{~min}$ at $37^{\circ} \mathrm{C}$.

NOTE: The detachment solution contains proteolytic and collagenolytic enzymes in 1x PBS, $0.5 \mathrm{mM}$ ethylenediaminetetraacetic acid (EDTA), and $3 \mathrm{mg} / \mathrm{L}$ phenol red. Reduce the pre-warming time of the cell detachment solution to a minimum as this will be inactive after $1 \mathrm{~h}$ at $37^{\circ} \mathrm{C}$. Cover the whole cell layer to obtain optimal cell detachment.

4. Check the detachment of cells using an inverted microscope.

5. Transfer all detached cells to a $50 \mathrm{~mL}$ tube prefilled with $10 \mathrm{~mL}$ of cell culture medium (same as used in step 1.1.1.) and resuspend the cells by pipetting.

6. Place the remaining cell suspension on a horizontal roller mixer at RT and proceed to the labelling step.

2. Live cell labelling of target cells

1. Dilute $1 \mu \mathrm{L}$ of $5 \mathrm{mM} \mathrm{CFSE}$ (supplied in dimethyl sulfoxide, DMSO) in $1 \mathrm{~mL}$ of $1 \times$ PBS pre-warmed at $37^{\circ} \mathrm{C}$ to obtain the $5 \mu \mathrm{M}$ ready-touse CFSE labelling solution.

NOTE: For optimal staining results, use freshly prepared solutions.

2. Prepare a ready-to-use DNA staining solution (Table of Materials and Reagents) in $1 \times$ PBS and store it at $2-6^{\circ} \mathrm{C}$ protected from light.

NOTE: For optimal staining results, use freshly prepared solutions.

3. Get the cells from horizontal roller mixer (step 1.1.6.) and pellet the cells at $300 \mathrm{x} g$ for $10 \mathrm{~min}$. Remove the supernatant and resuspend the cells in $10 \mathrm{~mL}$ of $1 \times$ PBS.

4. Rinse the cells again with $1 \times$ PBS and resuspend the cell pellet in $500 \mu \mathrm{L}$ ready-to-use CFSE labelling solution.

5. Incubate the cells at $37^{\circ} \mathrm{C}$ for $15 \mathrm{~min}$ and collect the cells after centrifugation at $300 \times \mathrm{g}$ for $3 \mathrm{~min}$.

6. Resuspend the labelled cells in $1 \mathrm{~mL}$ of pre-warmed cell culture medium and allow the cells to regenerate at $37^{\circ} \mathrm{C}$ for $30 \mathrm{~min}$.

7. Harvest the cells by centrifugation at $300 \times g$ for $3 \mathrm{~min}$ and resuspend the cell pellets in $1 \mathrm{~mL}$ of ready-to-use DNA staining solution at $37^{\circ} \mathrm{C}$ for $10 \mathrm{~min}$.

8. Pellet the cells, remove the supernatant and resuspend the cells in $4 \mathrm{~mL}$ of $1 \mathrm{x}$ PBS. Assess the cell density using a hemocytometer and check for fluorescence labelling using a fluorescence microscope equipped with 4',6-diamidino-2-phenylindole (DAPI) and fluorescein isothiocyanate (FITC) filters (Figure 2A and 2E).

9. Centrifuge the cells at $300 \times g$ for $3 \mathrm{~min}$ and resuspend the cell pellet according to the cell densities needed for the respective experiment as given in the next section and place on ice.

\section{Charging the wire}

NOTE: Cells can be isolated from target cell/peripheral blood spikings at the milliliter scale or by providing low number of cells at a microliter scale. Whereas the former approach allows for mimicking rare-cell condition in peripheral blood, the latter may be the preferred way to attach few cells for the purpose of protocol optimization/testing.

1. Charging the wire using a large volume of cell suspensions

1. Prepare a $2 \%$ BSA blocking solution by dissolving $0.8 \mathrm{~g}$ of BSA in $40 \mathrm{~mL}$ of $1 \times$ PBS (cell culture use). Dissolve BSA by initial vortexing and subsequent incubation at RT on a horizontal roller mixer for $10-20 \mathrm{~min}$. 
2. Rinse empty EDTA tubes/sodium heparin tubes with $2 \mathrm{~mL}$ of $2 \% \mathrm{BSA}$ to remove anticoagulant residues and discard the solution. Block the tube surface by incubation at RT with $5 \mathrm{~mL}$ of $2 \%$ BSA on a horizontal roller mixer at $15 \mathrm{rpm}$ for 30 min and discard the solution.

3. Dilute labelled cells (section 1.2.) to a density of 100000 cells $/ \mathrm{mL}$ and use $5 \mathrm{~mL}$ to charge the wire.

4. Add $5 \mathrm{~mL}$ of the labelled cell suspension ( 500000 cells in total) to the tube. Avoid bubbles when adding the cell suspension.

5. Remove the wire from the storage compartment as well as the rubber cap holding the wire and rinse it in 1x PBS (Figure 3).

6. Penetrate the rubber tube cap of the EDTA tube (step 2.1.4.) with the help of a syringe needle (20G) and insert the wire such that the functional part is fully immersed in the cell suspension when the cap is back on the tube and the tube placed on the tilted roller mixer. NOTE: The triple-helical functional part of the wire should be covered with cell suspension throughout the charging.

7. Rotate the tubes on a tilted roller mixer at $5 \mathrm{rpm}$ for $30 \mathrm{~min}$ to allow the cells to attach to the wire.

8. Rinse the wire with $5 \mathrm{~mL} 1 \times \mathrm{PBS}$ and store it in the dark at $2-6^{\circ} \mathrm{C}$ in a $15 \mathrm{~mL}$ tube containing $1 \times$ PBS until visual examination. NOTE: The functional part of the wire must always be submerged in PBS to avoid harming the cells.

2. Isolating target cells from artificial mixtures with peripheral blood (alternative charging method to: 2.1. Charging the wire using a large volume of cell suspensions)

1. Dilute labelled cells (section 1.2.) to obtain cell suspensions with high cell density (>1000 $000 \mathrm{cells} / \mathrm{mL}$ ), thereby keeping the volume of cell suspension added to the peripheral blood low.

2. Add 500 to 500000 cells to $5 \mathrm{~mL}$ of peripheral blood and mix them by inverting the tube.

3. Remove the wire from the storage compartment, remove the rubber cap holding the wire and rinse it in $1 \times$ PBS.

4. Penetrate a new tube cap with the non-functional part of the Device using a syringe needle (20G) such that the functional part is fully immersed in the spiked blood when the cap is back on the tube and the tube placed on the tilted roller mixer. NOTE: The triple-helical functional part of the wire should be covered with cell suspension throughout the charging.

5. Incubate the tube on the tilted roller mixer at $5 \mathrm{rpm}$ for $30 \mathrm{~min}$ at RT.

6. Rinse the wire 3 times in $1 \times$ PBS and store it in the dark in a $15 \mathrm{~mL}$ tube containing $1 \times$ PBS until visual examination. NOTE: The functional part of the wire must always be submerged to avoid harming the cells.

3. Charging the wire from low-volume cell suspensions (alternative charging method to: 2.1. Charging the wire using a large volume of cell suspensions)

1. Resuspend the labelled cells at 1000000 cells $/ \mathrm{mL}$ in $1 \times$ PBS.

2. Fix a $150 \mathrm{~mm}$ disposable glass Pasteur pipette horizontally on a rack.

3. Remove the wire from the storage compartment but keep the yellow rubber cap holding the wire.

4. Place the wire in the pipette such that the functionalized part is situated in the tip of the Pasteur pipette not touching the glass. NOTE: The tip of the wire should not stick out of the Pasteur pipette tip. Avoid plugging the rear end of the Pasteur pipette tip with the rubber cap holding the wire. If attached tight, cell suspensions cannot be loaded from the other side into the pipette tip.

5. Load $15 \mu \mathrm{L}$ of the cell suspension into the tip of the Pasteur pipette covering the functionalized part of the wire.

6. Incubate the wire for $10 \mathrm{~min}$. Manually quarter-turn the assembled wire/Pasteur pipette tip every minute.

7. Remove the wire from the Pasteur pipette tip, rinse it in $5 \mathrm{~mL}$ of $1 \times \mathrm{PBS}$ and store it in the dark at $2-6^{\circ} \mathrm{C}$ in a $15 \mathrm{~mL}$ tube containing $1 x$ PBS until visual examination.

NOTE: The functional part must always be submerged in $1 \times$ PBS to avoid harming the cells.

\section{Counting cells on the wire}

NOTE: Always keep the functional part of the wire submerged in 1x PBS to avoid harming the cells.

1. Use a grease pen to draw a rectangle area on a glass slide and add $500 \mu \mathrm{L}$ of $1 \times$ PBS

2. Bend the non-functional part of the wire and place it on the glass slide such that the functional part is immersed in $1 x$ PBS. NOTE: Fit the area of the rectangle and volume of $1 \times$ PBS to completely cover the functional part of the wire. Use a double-faced adhesive tape to mount the non-functional part of the wire on the slide.

3. Visually inspect both sides of the wire to enumerate the captured cells (Figure 2B and 2F) NOTE: The presence of cells is determined using a fluorescence microscope equipped with filters for DAPI and FITC. Both sides of the wire can be inspected and the number of cells either assessed (for high cell numbers) or counted (only feasible if low numbers of cells are attached to the wire). This step can be skipped if enumeration of cells is not necessary.

4. After scanning, place the wire back into the $15 \mathrm{~mL}$ tube containing the $1 \times$ PBS (see Note of 2.3.6. and section 3.), store it the wire in dark. NOTE: Most of the non-functional part of the wire can be cut (including the bend) and removed easing storage.

\section{Detachment and recovery of target cells}

NOTE: Detachment of the cells shall be done within $4 \mathrm{~h}$ after isolation.

1. Dissolve $4 \mathrm{mg}$ of the release buffer component (Table of Materials and Reagents) per $\mathrm{mL}$ of $1 \times \mathrm{PBS}$ and filter the solution through a $0.2 \mu \mathrm{m}$ sterile filter to obtain the ready-to-use buffer.

NOTE: The polymer of the wire is composed of a hydrogel which is functionalized with anti-EpCAM antibodies allowing binding to EpCAMpresenting target cells. The release buffer contains a carbon-oxygen proteolytic enzyme capable of cleaving the hydrogel. Proteolytic cleavage results in degradation of the polymer and, thus, detachment of captured cells.

2. Pre-warm the release buffer at $37^{\circ} \mathrm{C}$ for $5 \mathrm{~min}$.

3. Add $1.6 \mathrm{~mL}$ of release buffer to fill a $1.5 \mathrm{~mL}$ reaction tube.

NOTE: Tubes designed for $1.5 \mathrm{~mL}$ reaction volumes allow application of $1.6 \mathrm{~mL}$ which is necessary for submerging the functional part of the wire. 
4. Incubate the functional part of the wire in the release buffer at $37^{\circ} \mathrm{C}$ (water bath) for $20 \mathrm{~min}$. Use the rubber cap shipped with the wire instead of the tube cap to fix the wire in the $1.5 \mathrm{~mL}$ tube to avoid contamination during incubation in the water bath.

5. Transfer the wire/tube assembly to a shaker at RT and $500 \mathrm{rpm}$ for $15 \mathrm{~min}$. NOTE: The shaker has an orbit of $1.5 \mathrm{~mm}$.

6. Place the wire/tube assembly in a centrifuge and spin it at $300 \mathrm{xg}$ for $10 \mathrm{~min}$.

7. Remove the wire from the tube, close the cap and centrifuge the tube again at $300 \times g$ for $10 \mathrm{~min}$. NOTE: The wire can be stored in $1 x$ PBS at $2-6{ }^{\circ} \mathrm{C}$ in the dark for cell counting to assess detachment efficiency/check for cells remaining on the wire.

8. To reduce the volume of the cell suspension, remove all but $100 \mu \mathrm{L}$ (micromanipulation) or alternatively $300 \mu \mathrm{L}$ (cytocentrifugation and subsequent laser microdissection) of the supernatant and immediately proceed to single-cell sampling.

\section{Single-cell sampling}

1. Micromanipulation

NOTE: Single cells will be added to $2 \mu \mathrm{L}$ of cell lysis master mix allowing WGA. Prepare master mix according to the number of cells to be processed, calculate extra volumes for loss due to pipetting and place cell lysis master mix on ice.

1. Prepare the cell lysis master mix (components of WGA kit, Table of Materials and Reagents) according to the protocol outlined by Czyż et $a^{18}$. Briefly, mix $2.0 \mu \mathrm{L}$ of reaction buffer, $1.3 \mu \mathrm{L}$ of octylphenoxypolyethoxyethanol (10\% solution), 1.3 $\mu \mathrm{L}$ of $4-(1,1,3,3$ tetramethylbutyl)phenyl-polyethylene glycol (10\% solution), $2.6 \mu \mathrm{L}$ of a proteinase $\mathrm{K}$ solution, and $12.8 \mu \mathrm{L}$ RNase/DNase-free water to obtain a master mix for 10 samples (total volume $20 \mu \mathrm{L}$ ).

NOTE: For more samples, increase the volumes accordingly. The composition of cell lysis master mix differs from the one used in the alternative procedure utilizing laser microdissection samples (see 5.2.).

2. Use a grease pen to draw an area holding the cell suspension in place. Adjust area and volume if the cell density is too high (i.e. mark a larger area on the glass slide, load 1x PBS and an aliquot of the cell suspension).

3. Pipette the entire stained cell suspension (obtained in step 4.8.) onto the glass slide

4. Transfer the glass slide to a microscope equipped with a micromanipulator. Let the cells settle for 5 min (Figure 2D and 2H).

5. Prepare $0.2 \mathrm{~mL}$ PCR tubes loaded with $2.0 \mu \mathrm{L}$ of cell lysis master mix (see step 5.1.1.) and store it on ice.

6. Collect single cells in $1 \mu \mathrm{L}$ of $1 \times$ PBS using the micromanipulator and transfer the cells into a tube containing cell lysis master mix. NOTE: For transferring micromanipulated cells into the cell lysis buffer place the capillary directly into the $2 \mu \mathrm{L}$ of lysis solution and eject until bubbles can be seen.

7. Briefly spin down the sample at $2000 \times g$ for $3 \mathrm{~s}$ using a desktop microfuge to collect all liquid at the bottom of the tube. Place the samples on ice.

8. Directly proceed to single-cell WGA (see section 6. and Czyż et al. ${ }^{19}$ ).

2. Laser microdissection (alternative single-cell sampling method to: 5.1. Micromanipulation)

NOTE: The composition of the master mix used in this section differs from the one used in section 5.1 for micromanipulation. Single cells will be added to $4.5 \mu \mathrm{L}$ of cell lysis master mix (components of WGA kit, Table of Materials and Reagents) for WGA.

1. Prepare the cell lysis master mix according to Czyż et al. ${ }^{19}$ by mixing $5.0 \mu \mathrm{L}$ of reaction buffer, $1.3 \mu \mathrm{L}$ of octylphenoxypolyethoxyethanol ( $10 \%$ solution), $1.3 \mu \mathrm{L}$ of 4-(1,1,3,3-tetramethylbutyl)phenyl-polyethylene glycol (10\% solution), resp., $2.6 \mu \mathrm{L}$ of a proteinase $\mathrm{K}$ solution and $34.8 \mu \mathrm{L}$ of RNase/DNase-free water to obtain a master mix for 10 samples (total volume $45 \mu \mathrm{L}$ ). Place the master mix on ice. NOTE: For more samples, increase the volumes accordingly.

2. UV-treat membrane-coated slides suited for laser microdissection. Therefore, place the slides in a DNA cross linker device and expose to highest UV for about $10 \mathrm{~min}$.

3. Assemble the membrane-coated slide in a cytocentrifuge and cytospin the entire cell suspension at $300 \times g$ for $5 \mathrm{~min}$. NOTE: When using an in-liquid system, where the cells are cytocentrifuged onto the slide in solution, remove the supernatant after cytocentrifugation and apply a dry-spin at $1140 \mathrm{x} g$ for $1 \mathrm{~min}$.

4. Directly proceed to laser microdissection or let the cytospins air-dry overnight and freeze the samples at $-20^{\circ} \mathrm{C}$ for long term storage.

5. Pipette $4.5 \mu \mathrm{L}$ of cell lysis master mix into the cap of a $0.2 \mathrm{~mL}$ PCR tube and harvest single cells by means of laser microdissection.

6. Retrieve the PCR tube from the laser microdissection microscope and close the tube. Collect all liquid at the bottom of the tube by short-spin and place the sample on ice.

7. Proceed with single-cell WGA or store the isolated samples at $-80^{\circ} \mathrm{C}$ for up to 1 month before further processing.

\section{Adapter-linker based whole genome amplification ${ }^{18,19}$}

NOTE: Make sure all necessary master mixes (components of WGA kit, Table of Materials and Reagents) are prepared and stored on ice ready to use. Master mixes include the DNA digestion mix 1 for micromanipulated (see 5.1.) samples (containing $2.0 \mu \mathrm{L}$ of reaction buffer, 2.0 $\mu \mathrm{L}$ of Msel restriction enzyme and 16.0 $\mu \mathrm{L}$ of RNase/DNase-free water) or DNA digestion mix 2 for laser microdissection (see 5.2.) samples (containing $2.5 \mu \mathrm{L}$ of Msel restriction enzyme and $2.5 \mu \mathrm{L}$ of RNase/DNase-free water), pre-annealing master mix (containing $5.0 \mu \mathrm{L}$ of reaction buffer, $5.0 \mu \mathrm{L}$ of each of the preannealing PCR adapters, and $15.0 \mu \mathrm{L}$ of RNase/DNase-free water), ligation master mix (containing $30.0 \mu \mathrm{L}$ of pre-annealed PCR adapters, $10.0 \mu \mathrm{L}$ adenosine triphosphate solution, and $10.0 \mu \mathrm{L}$ T4 ligase solution) and primary PCR master mix (containing $30.0 \mu \mathrm{L}$ of a PCR buffer, $20.0 \mu \mathrm{L}$ of $10 \mathrm{mM}$ deoxynucleotide mix solution, $10.0 \mu \mathrm{L}$ of a polymerase mix and $340.0 \mu \mathrm{L}$ of RNase/DNase-free water). All volumes are given for preparing 10 samples. Adjust accordingly to the number of samples.

1. For cell lysis, place the micromanipulated/laser microdissection samples in a thermal cycler and run single-cell lysis by incubating the cell at $42{ }^{\circ} \mathrm{C}$ for $45 \mathrm{~min}, 65^{\circ} \mathrm{C}$ for $30 \mathrm{~min}$ and $80^{\circ} \mathrm{C}$ for $10 \mathrm{~min}$.

NOTE: Use a thermal cycler with a heated lid. Cell lysis can be done O/N for 10 to $15 \mathrm{~h}$. In that case, omit the incubation step at $65^{\circ} \mathrm{C}$. 
2. Run pre-annealing of the PCR adapters. Therefore, incubate the pre-annealing master mix in a thermal cycler at $65^{\circ} \mathrm{C}$ for 1 min followed by further 49 cycles, $1 \mathrm{~min}$ each, with progressively decreasing the temperature by $1^{\circ} \mathrm{C} /$ cycle. After 50 cycles $\left(\right.$ at $15^{\circ} \mathrm{C}$ ), incubate the master mix at $15{ }^{\circ} \mathrm{C}$ until further use.

NOTE: This step is necessary to generate asymmetric adapters suitable for ligation (see step 6.6.) with single-cell DNA subjected to Msel restriction digest.

3. After cell lysis, spin down the lysed samples at $2000 \times \mathrm{g}$ for $3 \mathrm{~s}$ to collect all liquid at the bottom and place it on ice.

4. To fragment DNA, add $2 \mu \mathrm{L}$ of the DNA digestion mix 1 to each lysed micromanipulated sample or $0.5 \mu \mathrm{L}$ of the DNA digestion mix 2 to the laser microdissection sample and run restriction digest. Use a thermal cycler with a heated lid at $37^{\circ} \mathrm{C}$ for 5 min followed by a restriction enzyme inactivation step at $65^{\circ} \mathrm{C}$ for $5 \mathrm{~min}$.

NOTE: Digestion at $37^{\circ} \mathrm{C}$ may be extended to $3 \mathrm{~h}$. This is the only protocol step differing between samples obtained from micromanipulation and samples obtained from laser microdissection.

5. Spin down the samples to collect all liquid at the bottom and place it on ice.

6. For ligating restriction digested DNA and pre-annealed adapters, add $5.0 \mu \mathrm{L}$ of the ligation master mix to each digested DNA sample and ligate it in a thermal cycler at $15^{\circ} \mathrm{C}$ for $1 \mathrm{~h}$. NOTE: This step can be extended to $12 \mathrm{~h}$ or performed O/N.

7. Spin down the samples to collect all liquid at the bottom and place it on ice.

8. For WGA add $40.0 \mu \mathrm{L}$ of primary PCR master mix to each of the ligation products and run WGA in a thermal cycler with a heated lid as follows:First, incubate the samples at $68^{\circ} \mathrm{C}$ for $3 \mathrm{~min}$. Second, cycle for 15 times at $94^{\circ} \mathrm{C}$ for $40 \mathrm{~s}, 57^{\circ} \mathrm{C}$ for $30 \mathrm{~s}$ and $68^{\circ} \mathrm{C}$ for $1 \mathrm{~min} 30 \mathrm{~s}+1$ s/cycle. Then add 9 cycles at $94^{\circ} \mathrm{C}$ for $40 \mathrm{~s}, 57^{\circ} \mathrm{C}+1{ }^{\circ} \mathrm{C} /$ cycle for $30 \mathrm{~s}, 68^{\circ} \mathrm{C}$ for $1 \mathrm{~min} 45 \mathrm{~s}+1 \mathrm{~s} / \mathrm{cycle}$. Thereafter, cycle for 23 times at 94 ${ }^{\circ} \mathrm{C}$ for $40 \mathrm{~s}, 65^{\circ} \mathrm{C}$ for $30 \mathrm{~s}, 68^{\circ} \mathrm{C}$ for $1 \mathrm{~min} 53 \mathrm{~s}+1 \mathrm{~s} /$ cycle. Finally, perform a final extension at $68^{\circ} \mathrm{C}$ for 3 min $40 \mathrm{~s}$ and chill the samples to 4 ${ }^{\circ} \mathrm{C}$.

9. Spin down the samples to collect all liquid at the bottom and check the DNA quality or store the samples at $-20^{\circ} \mathrm{C}$ or $-80^{\circ} \mathrm{C}$ for long-term storage.

\section{Quality control of WGA products}

NOTE: Check the quality of WGA products based on the range of the DNA smear and the number of amplification products after running a 4plex QC-PCR ${ }^{5}$. Run WGA aliquots and respective QC-PCR samples on a $1.0 \%$ agarose gel for evaluation.

1. Prepare $100 \mu \mathrm{M}$ stock solutions of all primers used for 4 plex quality control PCR (Table 1). Add $8 \mu \mathrm{L}$ of every primer to $136.0 \mu \mathrm{L}$ of PCRgrade water to generate $200 \mu \mathrm{L}$ of primer pool. Vortex the solution for $3 \mathrm{~s}$, spin it down at $2000 \times \mathrm{g}$ for $3 \mathrm{~s}$ and aliquot $20 \mu \mathrm{L}$ for storage at -20 ${ }^{\circ} \mathrm{C}$.

2. Use standard PCR kits to prepare a multiplex PCR master mix containing $6.0 \mu \mathrm{L}$ of $2 x \mathrm{PCR}$ components (except primers), $4.5 \mu \mathrm{L}$ of PCRgrade water and $0.5 \mu \mathrm{L}$ of the primer pool.

3. Add $1.0 \mu \mathrm{L}$ of the WGA products, spin it down and run PCR at $94{ }^{\circ} \mathrm{C}$ for 2 min followed by 35 cycles of denaturation at $94{ }^{\circ} \mathrm{C}$ for 1 min, primer annealing at $56{ }^{\circ} \mathrm{C}$ for $1 \mathrm{~min}$ and primer extension at $72{ }^{\circ} \mathrm{C}$ for $1 \mathrm{~min} 30 \mathrm{~s}$ and a final extension step at $72{ }^{\circ} \mathrm{C}$ for $7 \mathrm{~min}$. Chill it to $4{ }^{\circ} \mathrm{C}$, spin it down and place the samples on ice for gel analysis the same day or at $-20^{\circ} \mathrm{C}$ for later analysis. NOTE: Chilling in the thermal cycler can be performed at $12{ }^{\circ} \mathrm{C}$ to increase longevity of Peltier elements.

4. Analyze WGA products (obtained from 6.8.) and respective 4plex QC-PCR products on an agarose gel ${ }^{5}$.

\section{Representative Results}

Cells after CFSE and nucleic staining can be evaluated using an immunofluorescence microscope equipped with filters for DAPI and FITC. Nuclei present with a bright counterstain in the DAPI channel whereas cytoplasm of the cells show uniform labelling with CFSE with heterogeneous inter-cell intensity (Figure $2 \mathrm{~A}$ and $2 \mathrm{E}$ ). Similar shape and staining intensities are expected from cells attached to the wire (Figure $\mathbf{2 B}$ and $\mathbf{2 F}$ ) as well as detached from the wire and recovered on a slide (Figure $\mathbf{2 D}$ and $\mathbf{2 H}$ ).

High cell densities (e.g. >1 000000 cells $/ \mathrm{mL}$ ) may result in total coverage of the wire with cells when charging the wires. However, lower cell densities, changes in rotation speed during incubation, and the use of different cell lines affect the isolation efficiency and need to be tested separately. When the wires were incubated with $5 \mathrm{~mL}$ of HT-29 cells at 100000 cells/ mL as described in section 2.1 ., a mean of $254 \pm 103 \mathrm{cells}$ $(n=5)$ were captured on the wires. With the same experiment using LNCaP cells, a mean of $440 \pm 319$ cells $(n=5)$ per wire was obtained.

Presenting 500, 5000 , and $50000 \mathrm{HT}-29$ cells in a background of $5 \mathrm{~mL}$ of peripheral blood to wires (according to protocol section 2.2.) resulted in the capture of $75 \pm 18$ cells, $25 \pm 9$ cells, and $47 \pm 57$ cells $(n=3$, each), respectively. If the wire is charged with $15 \mu \mathrm{L}$ of cell suspension ( 1 000000 cells $/ \mathrm{mL}$ ) according to the protocol in section 2.3., up to 1000 (HT-29) cells may attach to a wire.

Cell detachment efficiencies ranged from $81 \%$ in HT-29 cells (range $54.9 \%-93.2 \%$, and $n=5$ ) to $81 \%$ (range $63.51 \%-92.87 \%, n=6$ ) and $91 \%$ (range $84.7 \%-95.3 \%, n=6$ ) in LNCaP and VCaP cells, respectively. Similarly, the recovery of detached cells differs between cell lines: A mean of $28 \%$ of detached HT-29 cells were recovered by cytocentrifugation. Whereas the recovery rate for LNCaP was lower than $10 \%$, the mean recovery rate for $\mathrm{VCaP}$ cells was $55 \%$.

Approximately $75 \%$ of single cells subjected to WGA yield high quality WGA products: This is 1) smear of WGA products ranging from 0.1 to $>1$ $\mathrm{kb}$ (Figure 4, top panel) and 2) three or four bands in the 4plex quality control PCR (Figure 4, bottom panel). WGA products can be used for 1 ) array-CGH profiling meeting the quality criteria for single-cell array-CGH profiles ${ }^{6,7}$ and 2 ) targeted NGS after re-amplification WGA ${ }^{7}$. 


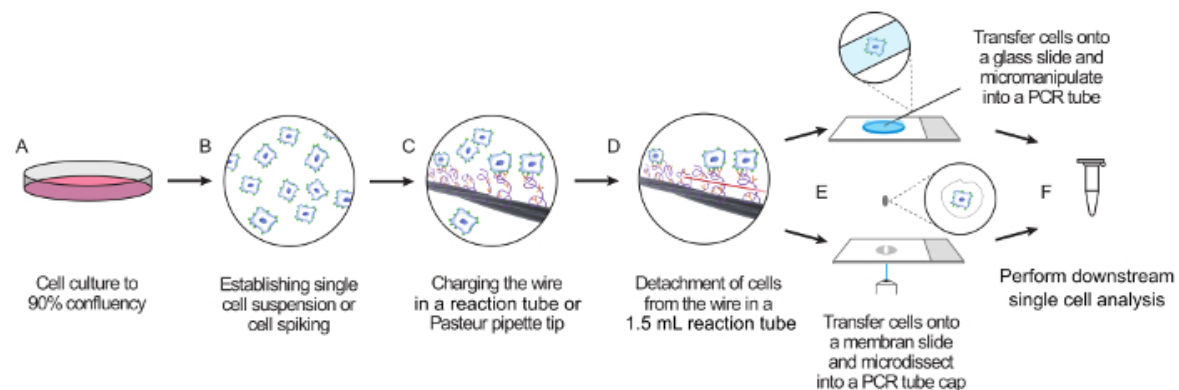

Figure 1: Workflow for isolating and recovering target cells for single-cell analysis. (A) Cells are cultured to $90 \%$ confluency and (B) harvested to obtain a single-cell suspension. After staining with CFSE and nucleic stain, (C) the functionalized wire is incubated in the presence of the cells either in a volume of $5 \mathrm{~mL}$ using reaction tubes or in a low volume using a Pasteur pipette tip. The latter allows for application of cell suspension volumes as low as $15 \mu \mathrm{L}$. (D) Cells need to be detached within $4 \mathrm{~h}$ after charging. Therefore, the wire is placed into a $1.5 \mathrm{~mL}$ reaction tube filled with release buffer. After $15 \mathrm{~min}$ incubation on a rocker and $10 \mathrm{~min}$ centrifugation, the wire is removed and the cell suspension is centrifuged to pellet the cells. (E) Recovered cells are either transferred to a glass slide for single-cell micromanipulation (top) or cytocentrifuged onto a membrane-coated slide and forwarded to laser microdissection (bottom). (F) Finally, harvested single cells are amplified by means of whole genome amplification (WGA). WGA products are compatible with array-CGH and targeted NGS downstream analysis.EpCAM epitope: green circle on cell surface. Functionalized wire: Device, grey triple-helical wires. Polymer: purple lines. Anti-EpCAM antibodies: orange. Release buffer activity: red arrow. Grease marker to hold cell suspension in place: dark blue ellipse. Recovered cell suspension: light blue. Capillary for micromanipulation: black line. Magnification: recovered cell harvested by micromanipulation, cytospin on membrane-covered slide containing recovered cells (grey filled ellipse). Magnification: recovered cell being laser microdissected (grey circular line: membrane from membrane slide serving as backbone for laser microdissection), objective with laser beam (blue line approaching the membrane slide from below). Please click here to view a larger version of this figure.
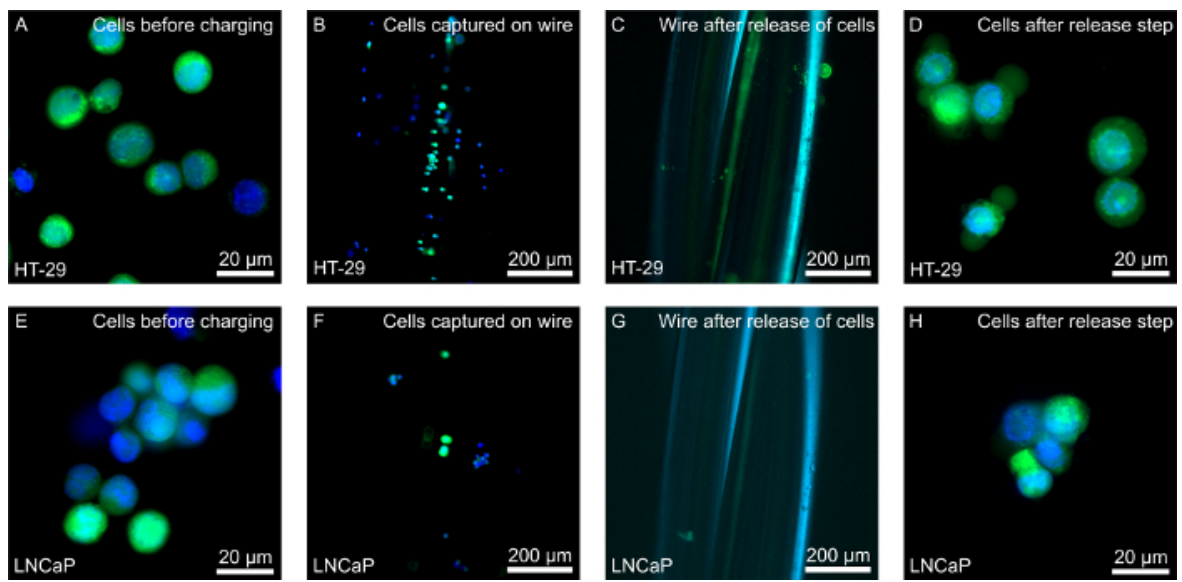

Figure 2: Visualizing labelled cells. (A,E) Cells before charging: Cells are labelled with CFSE and counterstained with a DNA intercalating dye showing a range of CFSE (green) signal intensity. (B,F) Labelled cells captured on the wire. $(\mathbf{C}, \mathbf{G})$ Wire after cell-detachment procedure. (D,H) Cells detached from wire and recovered by cytocentrifugation onto a slide. CFSE: FITC channel (green). DNA stain: DAPI channel (blue). Please click here to view a larger version of this figure. 


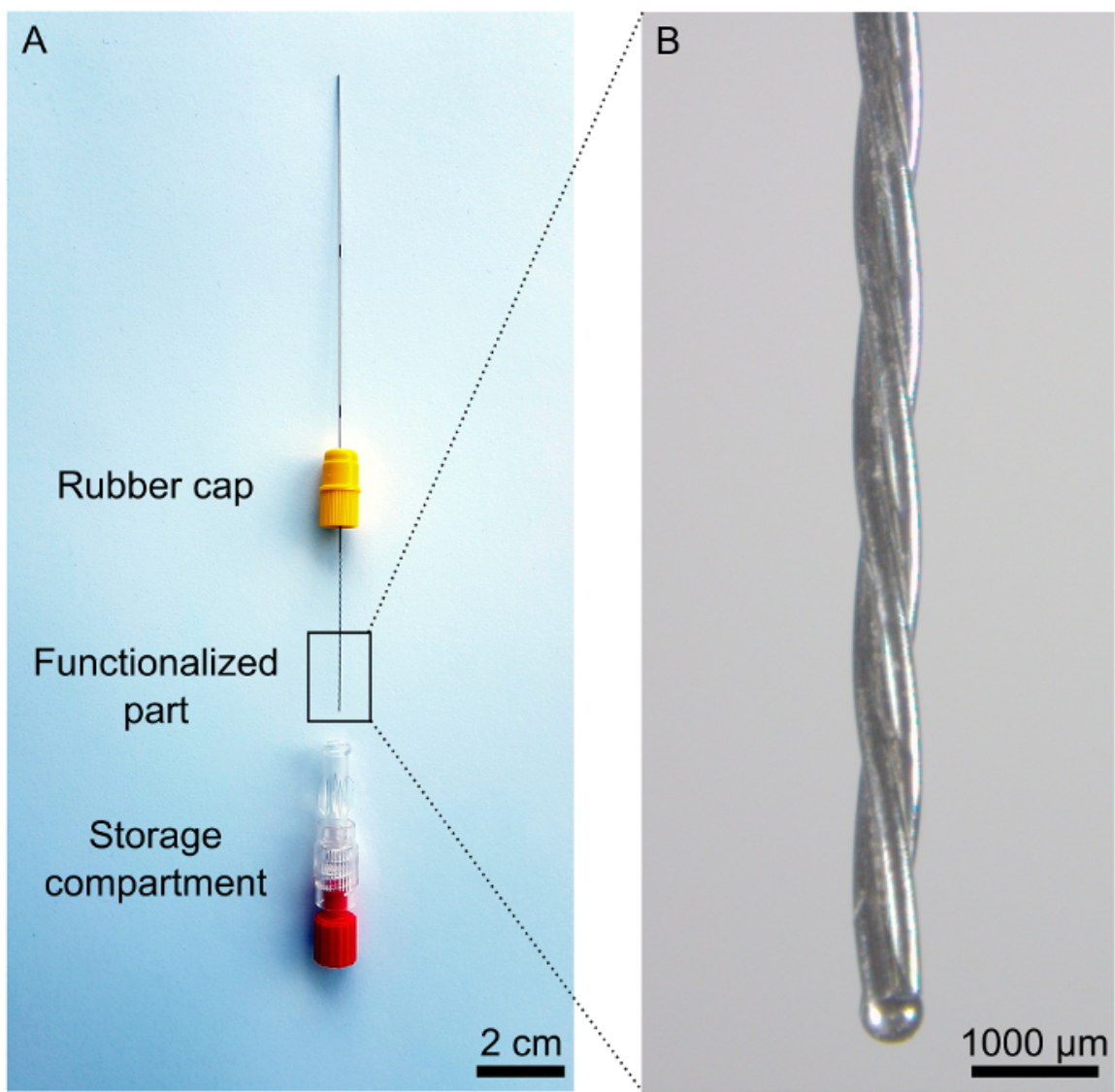

Figure 3: Wire and storage compartment. (A) Compartments of the wire. (B) Detail of the functionalized part. Please click here to view a larger version of this figure. 


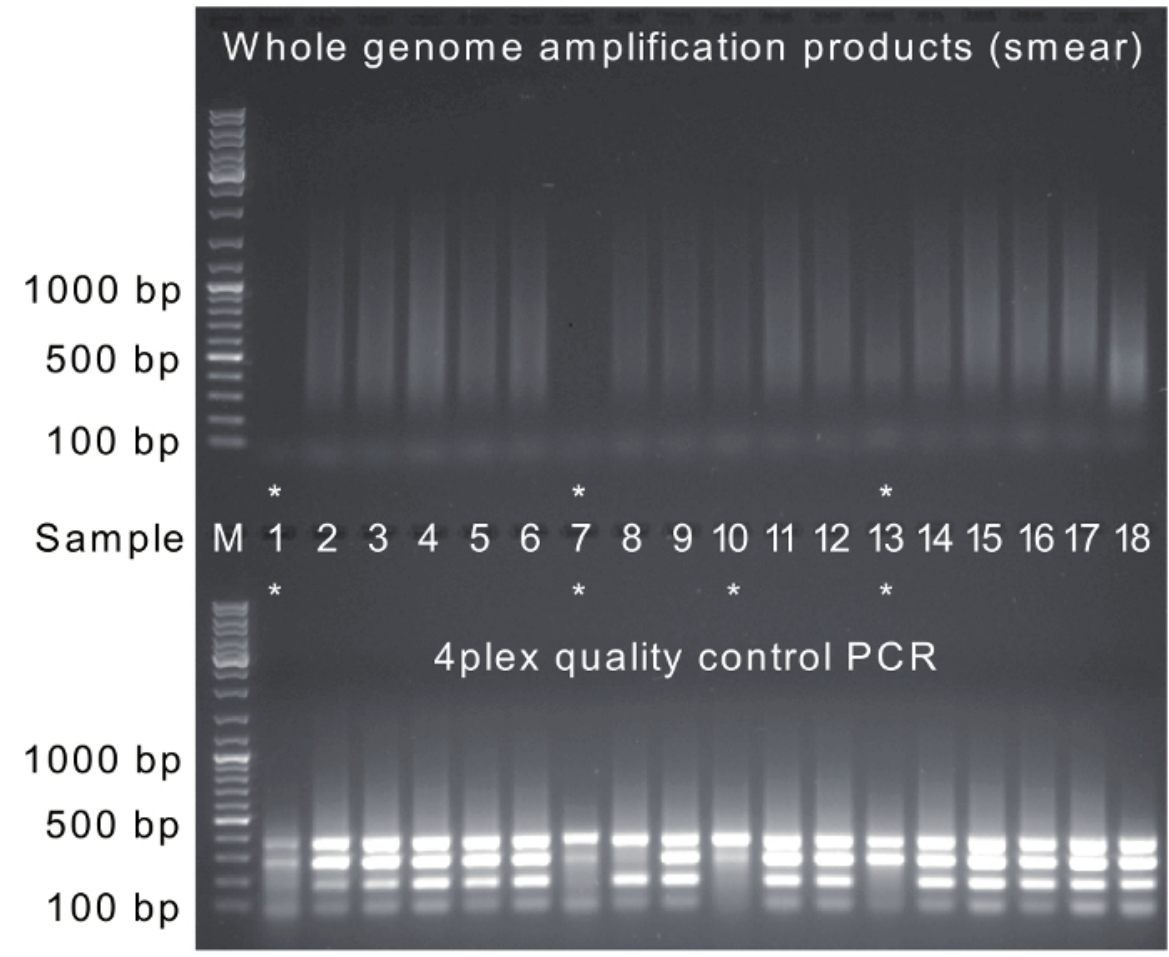

Figure 4: Quality control of WGA products obtained from single micromanipulated cells. Top panel: WGA products obtained from single cells typically result in DNA smears ranging from $0.2 \mathrm{~kb}$ to $>1.0 \mathrm{~kb}$ with a peak intensity at around $0.5 \mathrm{~kb}$. Samples number 1,7 and 13 (indicated with asterisks) show suboptimal or no DNA smears. Bottom panel: WGA products are of sufficient quality if the 4plex PCR yields three or four of four PCR products (at 100, 200, 300, and $400 \mathrm{bp}$ ). Samples 1, 7, 10, and 13 show fewer than three bands and would be excluded from further analysis. Lane M contains a 100 bp ladder and asterisks indicate the samples of insufficient WGA product quality. Please click here to view a larger version of this figure.

\begin{tabular}{|l|l|}
\hline Primer sequence & NOTE \\
\hline 5'-gtt cca ata tga ttc cac cc-3' & 100 bp forward primer \\
\hline 5'-ctc ctg gaa gat ggt gat gg-3' & 100 bp reverse primer \\
\hline $5^{\prime}$-agg tgg agc gag gct agc-3' & 200 bp forward primer \\
\hline $5^{\prime}$-ttt tgc ggt gga aat gtc ct-3' & 200 bp reverse primer \\
\hline 5'-agg tga gac att ctt gct gg-3' & 300 bp forward primer \\
\hline 5'-tcc act aac cag tca gcg tc-3' & 300 bp reverse primer \\
\hline $5^{\prime}$-aca gtc cat gcc atc act gc-3' & 400 bp forward primer \\
\hline $5^{\prime}$-gct tga caa agt ggt cgt tg-3' & 400 bp reverse primer \\
\hline
\end{tabular}

Table 1: Primer sequences for 4plex quality control PCR

\section{Discussion}

The described protocol aims at retrieving cells from a functionalized wire (referred to as Device) for ex vivo single-cell genomic analysis. We tested three EpCAM-positive cell lines (HT-29, LNCaP, and VCaP), but in principle, this method can be applied to any cell line expressing EpCAM. EpCAM-positive target cells can be presented to the Device as pure cell suspension (see 2.1.) or mixed into a surplus of background cells (e.g. peripheral blood, see 2.2.). Whereas especially the latter might be used to test isolation capacities under rare cell conditions, fine tuning of the number of cells attached to the wire can be done using the described low-volume approach (see 2.3.). As differences between cell lines are to be expected, suitable cell densities for charging the wire, rotation speed as well as incubation time need to be tested empirically by evaluating the number of attached cells using an immunofluorescence microscope.

For genomic downstream applications at the single-cell level WGA, is required. The WGA method of choice may differ between labs and, in principle, our method is open to all methods than can handle samples obtained from micromanipulation or laser microdissection. In this protocol, we use a method based on enzymatically fragmented DNA due to a better performance as compared to a heat-fragmentation based WGA ${ }^{7}$. Optional, single cells can be forwarded to isothermal WGA allowing subsequent DNA profiling ${ }^{20,21}$.

The described protocol aims at recovering intact cells after being attached to a new generation of functionalized wires for genomic single-cell analysis. The first generation of functionalized wires, which also represent the only CE-approved in vivo enrichment devices on the market so 
far, were used for enumerating CTCs in metastasized cancer patients. Previous publications and our own data suggest the in vivo isolation technique to be more sensitive compared to the current gold standard technology ${ }^{2}$. Thus, equipping this in vivo isolation technique with a recovery feature as realized in the Device allows combining high CTC recovery with characterization at the single-cell level.

However, the Device is not cleared for the use in patients, thus, clinical data are not available. Ex vivo applications (i.e. isolating CTCs from peripheral blood after sampling) are not recommended as the technology is adapted to the settings present in the cubital vain, e.g. low diameter of the vain (increasing the probability of direct contact between CTCs and catching antibodies) and long retention time ( 30 min, allowing $2-3 \mathrm{~L}$ of blood to pass the wire). However, as outlined in section 2.2. target cells can also be isolated from mixed samples ${ }^{7}$.

A current limitation of the method is the inefficient recovery of unfixed cells after detachment from the wires. This, however, might be improved by a cell fixation step prior to the detachment treatment.

In summary, this protocol is a first step towards the combined use of an in vivo isolation technique with cell recovery for genetically characterizing single cells. Further efforts need to address the optimization of the cell recovery and clearance for its application in patients ${ }^{1,2}$. However, personalized medicine for treatment monitoring and therapy decisions is beyond enumeration of CTCs. Thus, this method is a first step towards genomic CTC characterization at the single cell level.

Applications towards single-cell transcriptome analysis seem feasible as intact cells are harvested. However, it remains to be assessed whether the recovering procedure has an impact on RNA integrity (e.g. forwarding recovered single cells to direct lysis followed by RT-qPCR ${ }^{22}$ ). If successful, characterization of single cells (e.g. CTCs) can be shifted to the transcriptome level, allowing more detailed analyses. In this regard, RNA-seq using Smart-seq2 provides a valuable tool for RNA downstream analysis of single cells as the preamplified cDNA (obtained during RNA-seq library preparation) can be subjected to quantitative PCR. This will allow a combined target and screening-based analysis of single recovered cells $^{22,23}$.

The current functionalized wires are based on anti-EpCAM antibodies which is a widely used epithelial marker for positive selection of CTCs ${ }^{24}$. As several CTCs might downregulate epithelial markers such as cytokeratins or EpCAM ${ }^{25}$, adding antibodies such as HER2/new would increase the chance of CTC isolation. Several antibody based enrichment strategies have been developed and reviewed by Ferreira et al. in $2016^{26}$. A mixture of antibodies immobilized on a wire could be a future improvement of the technology leading to the isolation of a higher number and additional subtypes of CTCs.

It is mandatory for all steps involving wire handling to keep the functional part of the wire submerged in solution in order to maintain its functionality. We recommend to place the wire in 1x PBS during evaluation (microscope; e.g. steps 3.1. - 3.3.) and storage. In order to avoid inappropriate staining, we recommend using freshly prepared staining solution in steps 1.2.1. and 1.2.2. Weakly stained cells hamper cell counting on the wire and may lead to the underestimation of the attached cells.

It is necessary to avoid plugging the Pasteur pipette with the rubber cap when inserting the wire in the Pasteur pipette for subsequent loading of the cell suspension (step 2.3.4.). The rubber cap is used to hold the wire in place so that the functional part is situated inside the tip of the Pasteur pipette. If the cap is attached too firmly to the rear of the Pasteur pipette, loading of the cell suspension is not possible. In this case, ease the cap such that the air which is displaced by the loaded cell suspension can leave the pipette.

Bending the wire is crucial for its orientation during the cell counting in steps 3.2. and 3.3. Mount the wires using the adhesive tape such that the non-functional end of the wire comes to lie to one side. After scanning of the entire length of the functional part, the wire is rolled $180^{\circ}$ so the other half of the functional wire can be scanned. This step is important for initial experiments to assess the number of cells on the wire. Once the number of cells for a certain cell line and procedure is evaluated, the procedure can be repeated without cell counting (e.g. only checking for presence of cells or omitting this step). Careful pipetting is crucial to avoid cell loss when reducing the volume of the supernatant in step 4.8. Make sure pipetting is done smoothly without causing turbulences to the pellet.

\section{Disclosures}

The authors have nothing to disclose.

\section{Acknowledgements}

This study was funded by the Austrian Science Fund (FWF), project-no. I 1220-B19 (to P.S.) as part of the ERANET project in Translational Cancer Research (TRANSCAN) "Circulating Tumour Cells as Biomarker for Minimal Residual Disease in Prostate Cancer (CTC-SCAN)". $\mathrm{PhD}$ candidate S.C. was trained within the frame of the PhD Program Molecular Medicine of the Medical University of Graz. The authors gratefully acknowledge Nina Schlögl, Daniel Kummer, Gabi Wendt, Claudia Chudak, Julia Schulz, and Johanna Schiller for their expert technical assistance. The authors thank Georg Peinhaupt for graphical design support.

\section{References}

1. Saucedo-Zeni, N. et al. A novel method for the in vivo isolation of circulating tumor cells from peripheral blood of cancer patients using a functionalized and structured medical wire. Int J Oncol. 41 (4), 1241-50 (2012).

2. Gorges, T. M. et al. Enumeration and Molecular Characterization of Tumor Cells in Lung Cancer Patients Using a Novel In Vivo Device for Capturing Circulating Tumor Cells. Clin Cancer Res. 22 (9), 2197-206 (2016).

3. Kuske, A. et al. Improved detection of circulating tumor cells in non-metastatic high-risk prostate cancer patients. Sci Rep-UK. 6 (1) (2016).

4. van Beers, E. H. et al. A multiplex PCR predictor for aCGH success of FFPE samples. Brit J Cancer. 94 (2), 333-7 (2006). 
5. El-Heliebi, A., Chen, S., \& Kroneis, T. Using Multiplex PCR for Assessing the Quality of Whole Genome Amplified DNA. Methods Mol Biol. 1347, 119-28 (2015).

6. Möhlendick, B. et al. A Robust Method to Analyze Copy Number Alterations of Less than $100 \mathrm{~kb}$ in Single Cells Using Oligonucleotide Array CGH. PLOS ONE. 8 (6), e67031 (2013).

7. Chen, S. et al. Catch and Release: rare cell analysis from a functionalised medical wire. Sci Rep-UK. 7, 43424 (2017).

8. Zhang, $\mathrm{H}$. et al. Enumeration and molecular characterization of circulating tumor cell using an in vivo capture system in squamous cell carcinoma of head and neck. Chin J Cancer Res. 29 (3), 196-203 (2017).

9. Carter, L. et al. Molecular analysis of circulating tumor cells identifies distinct copy-number profiles in patients with chemosensitive and chemorefractory small-cell lung cancer. Nat Med. 23 (1), 114-119 (2017).

10. Luca, F. D. et al. Mutational analysis of single circulating tumor cells by next generation sequencing in metastatic breast cancer. Oncotarget. (2016).

11. Aravanis, A. M., Lee, M., \& Klausner, R. D. Next-Generation Sequencing of Circulating Tumor DNA for Early Cancer Detection. Cell. 168 (4), 571-574 (2017).

12. Page, K. et al. Next Generation Sequencing of Circulating Cell-Free DNA for Evaluating Mutations and Gene Amplification in Metastatic Breast Cancer. Clin Chem. 63 (2), 532-541 (2017).

13. Kalinich, M. et al. An RNA-based signature enables high specificity detection of circulating tumor cells in hepatocellular carcinoma. $P$ Natl Acad Sci USA . 114 (5), 1123-1128 (2017).

14. Gorges, T. M. et al. Accession of Tumor Heterogeneity by Multiplex Transcriptome Profiling of Single Circulating Tumor Cells. Clin Chem. 62 (11), 1504-1515 (2016).

15. Sinkala, E. et al. Profiling protein expression in circulating tumour cells using microfluidic western blotting. Nat Commun. 8, 14622 (2017).

16. Morrow, C. J. et al. Tumourigenic non-small-cell lung cancer mesenchymal circulating tumour cells: a clinical case study. Ann Oncol. 27 (6), $1155-1160$ (2016).

17. Williamson, S. C. et al. Vasculogenic mimicry in small cell lung cancer. Nat Commun. 7, 13322 (2016).

18. Czyż, Z. T., Stoecklein, N. H., \& Polzer, B. Laser Microdissection of FFPE Tissue Areas and Subsequent Whole Genome Amplification by Ampli1 $^{\text {TM }}$. Methods Mol Biol. 1347, 141-162 (2015).

19. Czyż, Z. T., \& Klein, C. A. Deterministic Whole-Genome Amplification of Single Cells. Methods Mol Biol. 1347, 69-86 (2015).

20. Kroneis, T. et al. Automatic retrieval of single microchimeric cells and verification of identity by on-chip multiplex PCR. J Cell Mol Med. 14 (4), 954-969 (2010).

21. Kroneis, T. et al. Combined Molecular Genetic and Cytogenetic Analysis from Single Cells after Isothermal Whole-Genome Amplification. Clin Chem. 57 (7), 1032-41 (2011).

22. Kroneis, T., Jonasson, E., Andersson, D., Dolatabadi, S., \& Ståhlberg, A. Global preamplification simplifies targeted mRNA quantification. Sci Rep-UK. 7, 45219 (2017).

23. Picelli, S., Faridani, O. R., Bjorklund, A. K., Winberg, G., Sagasser, S., \& Sandberg, R. Full-length RNA-seq from single cells using Smartseq2. Nat Protoc. 9 (1), 171-81 (2014).

24. El-Heliebi, A., Heitzer, E., Kroneis, T., Chen, S., Haudum, C., \& Fuchs, J. Potential and Challenges of Liquid Biopsies. Mechanisms of Molecular Carcinogenesis - Volume 2. , 233-261 (2017).

25. Lamouille, S., Xu, J., \& Derynck, R. Molecular mechanisms of epithelial-mesenchymal transition. Nat Rev Mol Cell Bio. 15 (3), 178-196 (2014).

26. Ferreira, M. M., Ramani, V. C., \& Jeffrey, S. S. Circulating tumor cell technologies. Mol Oncol. 10 (3), $374-394$ (2016). 